\title{
Temperature dependence of water content of stratum corneum
}

\author{
T.S.SPENCER, C.E.LINAMEN, W.A.AKERS AND H.E.JONES* \\ Department of Dermatology Research, Letterman Army Institute of Research, Presidio of San Francisco, CA \\ 94129, and Department of Dermatology, * University of Michigan Medical Center, Ann Arbor, Michigan \\ $48 \mathrm{ro}$, U.S.A.
}

Accepted for publication 21 November 1974

\section{SUMMARY}

The water content of human stratum corneum has been measured gravimetrically in vitro in relation to relative humidity $(\mathrm{RH})$ and temperature. Water content increased with increasing RH. Stratum corneum water content increased $50 \%$ when the temperature was raised from 20 to $35^{\circ} \mathrm{C}$ at $\mathrm{RH}$ below $60 \%$. Temperature dependence decreased with increasing $\mathrm{RH}$ until there was essentially no temperature dependence at $90 \% \mathrm{RH}$. The conclusion is that temperature changes could significantly affect water content in vivo and pliability of skin at $\mathrm{RH}$ below $60 \%$.

Previous work has indicated the importance of water content of the skin in protecting the body from environmental assaults including water, ultraviolet exposure, detergents and chemical irritants (Blank, 1952; Singer \& Vinson, I966). Water content of stratum corneum has been defined as a function of relative humidity (Singer \& Vinson, 1966). We have studied the relationship between water content of stratum corneum and changes in temperature in vitro and report a previously undescribed temperature dependence of water content.

Blank (1952) showed that water content of stratum corneum varied with relative humidity (RH) and that the pliability of skin was reduced at $\mathrm{RH}$ below $60 \%$. He estimated that the critical point for pliability was about $10 \mathrm{mg}$ of water per $100 \mathrm{mg}$ of dry stratum corneum. In general, he observed that water loss from stratum corneum increased at high temperature, at low humidity, and in flowing air. Clinical studies by Gaul \& Underwood (195I) supported these observations and showed that chapping could be related to dew point which reflected temperature and humidity. Later work by Singer \& Vinson (1966) indicated that water content of stratum corneum varied with RH in a logarithmic relationship and did not depend on absolute humidity.

Middleton \& Allen (1973) proposed that the ability of stratum corneum to stretch prior to breaking is significantly less at lower temperatures. Wildnauer, Bothwell \& Douglass (I97I) demonstrated that decreased water content of stratum corneum has the same effect of reducing extensibility. Although

Correspondence address: Dr Thomas S. Spencer, Department of Dermatology Research, Letterman Army Institute of Research, Presidio of San Francisco, CA 94129, U.S.A. 
Middleton discounted water content as a major factor in his tests, the present report shows that water content of stratum corneum is reduced at lower temperatures and might contribute to the loss of extensibility observed by him at lower temperatures.

\section{MATERIALS AND METHODS}

Stratum corneum from the abdominal region of cadavers was separated by trypsinization (Kligman \& Christophers, 1963). Remaining epidermal tissue was gently removed from the membrane with a wool-tipped stick and the stratum corneum was stored over Drierite in a desiccator. Six mm diameter disks were cut from samples with a biopsy punch and were mounted on nichrome wire hooks. Hydration measurements were made in a $15 \times 15 \times 20 \mathrm{~cm}$ plastic chamber with a controlled environment. Within the chamber, up to six stratum corneum samples suspended from hooks were weighed on a balance wire extending down from a Cahn RG Electrobalance on top of the chamber. Transfer of samples to and from the balance wire was made by a slidewire inside the chamber so that all measurements were made without disturbing the environment of the chamber.

Humidity within the chamber was maintained by salt solutions which generate a constant $\mathrm{RH}$ from to to $35^{\circ} \mathrm{C}$ (Young, 1967). The following saturated solutions were used: magnesium chloride, $(\mathrm{RH}=30 \%)$, potassium carbonate $(40 \%)$, sodium nitrite $(60 \%)$, sodium chloride $(75 \%)$, potassium chloride $(83 \%)$, potassium nitrite $(93 \%)$, and potassium sulphate $(96 \%)$. The hydration chamber was mounted within a modified Hydro-Jac Incubator (Forma Scientific), which was coupled with a water bath to regulate the temperature of the incubator $\left( \pm 0 \cdot 2^{\circ} \mathrm{C}\right)$. Temperature was monitored with a 46 TU Telethermometer (Yellow Springs Instrument Co.), and humidity with Hydrodynamics narrowrange sensors located within the chamber. Changes in humidity and weight gain of samples were recorded simultaneously throughout the experiment.

Four samples from the same source were monitored on each run. Initially, samples were hung in the chamber and equilibrated over Drierite for at least $72 \mathrm{~h}$. The dry weight of each sample was taken within the chamber at $20^{\circ} \mathrm{C}$. The chamber was then opened and Drierite was replaced with salt solution. The closed system was allowed to equilibrate for $72 \mathrm{~h}$ at which time the weight had been stable for at least $24 \mathrm{~h}$. Samples were then weighed within the chamber and the temperature was raised. Again, samples were equilibrated for $72 \mathrm{~h}$ and weighed. This procedure was repeated for the humidities specified at $10,20,30$ and $35^{\circ} \mathrm{C}$.

Maximum hydration was determined by hydrating samples for $24 \mathrm{~h}$ over distilled water at $30^{\circ} \mathrm{C}$ until equilibrium was reached. Then warm water was placed in the sample chamber, raising the $\mathrm{RH}$ to $100 \%$, when the sample gained weight due to condensation. After equilibrium at $30^{\circ} \mathrm{C}$ for a second $24 \mathrm{~h}$, a steady state was reached at a measured $97 \% \mathrm{RH}$ and $92 \%$ weight gain. In previous studies with hydration at $97.5 \% \mathrm{RH}$, hydration had ranged between 90 and $106 \%$ weight gain for normal samples. Hence $92 \%$ hydration was taken as the maximum equilibrium weight gain in this study.

Hydration was monitored for ascending and descending temperatures for some samples, and no differences in the temperature dependence were observed. The observed hysteresis effects were small and were included in the data. Weight gain of samples was recorded as percent weight gain or mg of water per roo mg of dry stratum corneum.

\section{RESULTS}

Fig. I shows $\%$ weight gain or water content of stratum corneum in relation to temperature and $\mathrm{RH}$. Above $20 \% \mathrm{RH}$, mean water content of stratum corneum increases linearly with $\mathrm{RH}$ up to $60 \%$ $\mathrm{RH}$, then rises exponentially up to $95 \%$. 


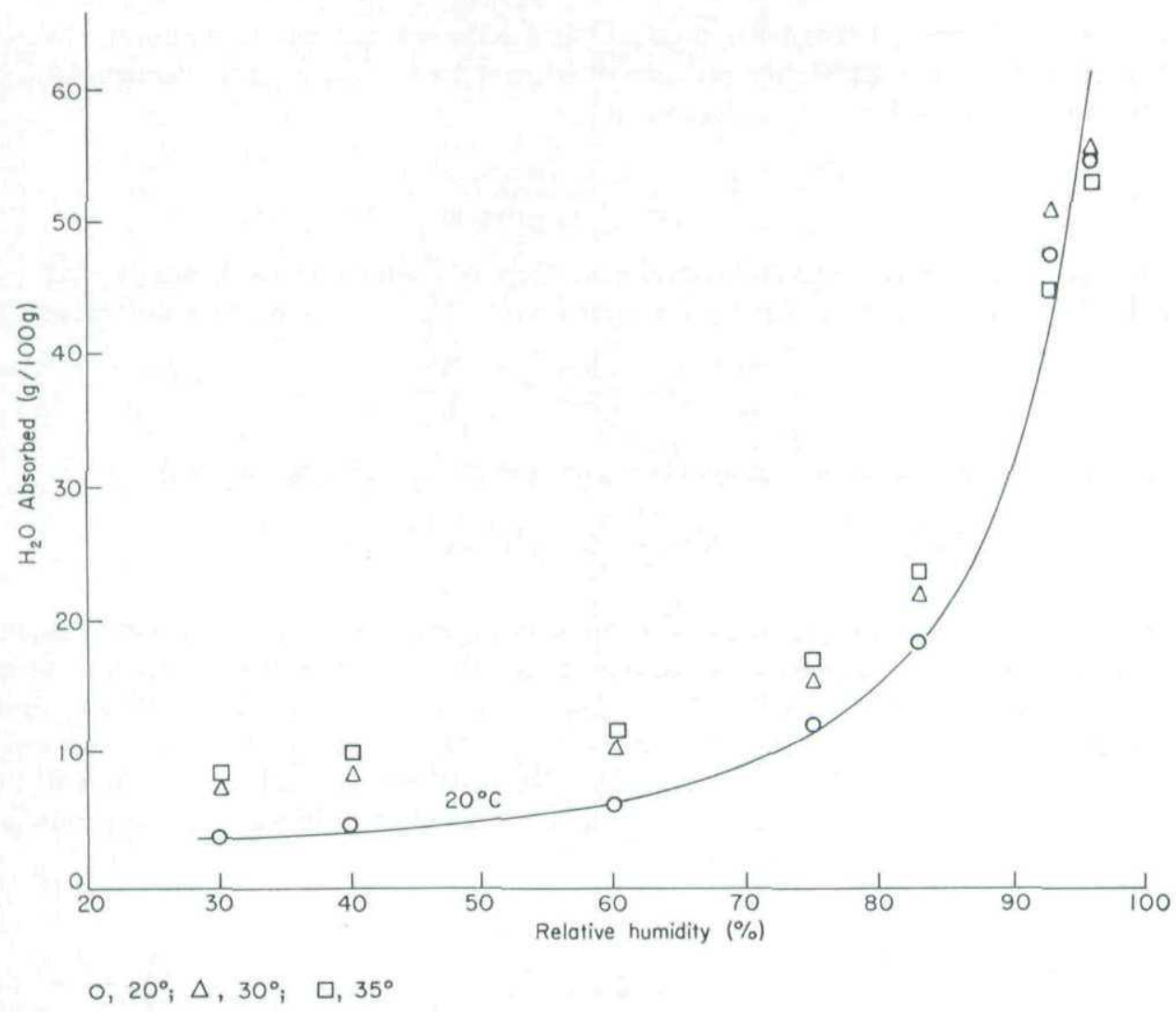

FIGURE I. Hydration of stratum corneum as a function of relative humidity. Investigated for 20 , 30 and $35^{\circ} \mathrm{C}$.

Water content of stratum corneum samples can be discussed in terms of the equilibrium constant $\mathrm{K}$ associated with the hydration reaction:

Dry stratum corneum $+\mathrm{H}_{2} \mathrm{O} \rightleftarrows$ Hydrated stratum corneum.

The equilibrium constant then becomes:

$$
\mathrm{K}^{\prime}=\frac{[\text { Hydrated stratum corneum }]}{[\text { Dry stratum corneum }]\left[\mathrm{H}_{2} \mathrm{O}\right]} .
$$

In the present work $\mathrm{RH}$ and, therefore, water concentration in air can be considered constant; hence, $\left[\mathrm{H}_{2} \mathrm{O}\right]$ can be included in $\mathrm{K}^{\prime}$ as $\mathrm{K}=\mathrm{K}^{\prime}\left[\mathrm{H}_{2} \mathrm{O}\right]$. Dry stratum corneum can be described as the number of sites available for hydration (total sites) minus the number of sites occupied by $\mathrm{H}_{2} \mathrm{O}$ (hydrated sites). Thus,

$$
\mathrm{K}=\frac{[\text { Hydrated sites }]}{[\text { Total sites }- \text { Hydrated sites }]} .
$$

Sites occupied by $\mathrm{H}_{2} \mathrm{O}$ per mg sample can be expressed as $\%$ hydration or $\mathrm{mg}\left(\mathrm{H}_{2} \mathrm{O}\right) / \mathrm{roO} \mathrm{mg}$ dry 
stratum corneum. Taking the extent of hydration at $97 \% \mathrm{RH}$ as the maximum equilibrium hydration* of undamaged stratum corneum in the presence of water vapour as discussed in the methods section, total sites can be expressed as $92 \%$ hydration and

$$
\mathrm{K}=\frac{\% \text { hydration }}{92-\% \text { hydration }} \text {. }
$$

Temperature dependence is then reflected in the thermodynamic quantity enthalpy $\left(\Delta \mathrm{H}^{\circ}\right)$ which is related to $\mathrm{K}$ by the equilibrium expression for free energy $\left(\Delta \mathrm{G}^{\circ}\right)$ at constant pressure (Moore, 1962),

$$
\frac{\mathrm{d} \Delta \mathrm{G}^{\circ}}{\mathrm{d}(\mathrm{l} / \mathrm{T}}=\frac{\mathrm{d} \ln \mathrm{K}}{\mathrm{d}(\mathrm{l} / \mathrm{T})}=\frac{-\Delta \mathrm{H}^{\circ}}{\mathrm{R}}
$$

where $\mathrm{R}$ is the gas constant under conditions of constant pressure. Integration yields

$$
\ln \mathrm{K}=\frac{-\Delta \mathrm{H}^{\circ}}{\mathrm{R}}(\mathrm{I} / \mathrm{T})+\mathrm{C} \text {. }
$$

$\mathrm{C}$ is a constant of integration which includes the constant $\mathrm{H}_{2} \mathrm{O}$ concentration in air as well as entropic factors. Over the small temperature range in this study, $\Delta \mathrm{H}^{\circ}$ can be assumed constant, and $\operatorname{lnK}$ is plotted versus $1 / \mathrm{T}$ with slope $-\Delta \mathrm{H}^{\circ} / \mathrm{R}$ (Fig. 2). The r-correlations for all plots of $\ln \mathrm{K}$ are significant $(\propto<0.05)$ with respect to $1 / \mathrm{T}$, except for I run at $60 \% \mathrm{RH}(\propto<0.10)$ and runs at 93 and $95 \%$ $\mathrm{RH}$ in which the slope approaches zero. The range of $\mathrm{K}$ values for each $\mathrm{RH}$ is also indicated (Fig. 2). The enthalpies determined from plots like those in Fig. 2 are plotted in Fig. 3 as a function of RH. Ranges shown are $95 \%$ confidence limits.

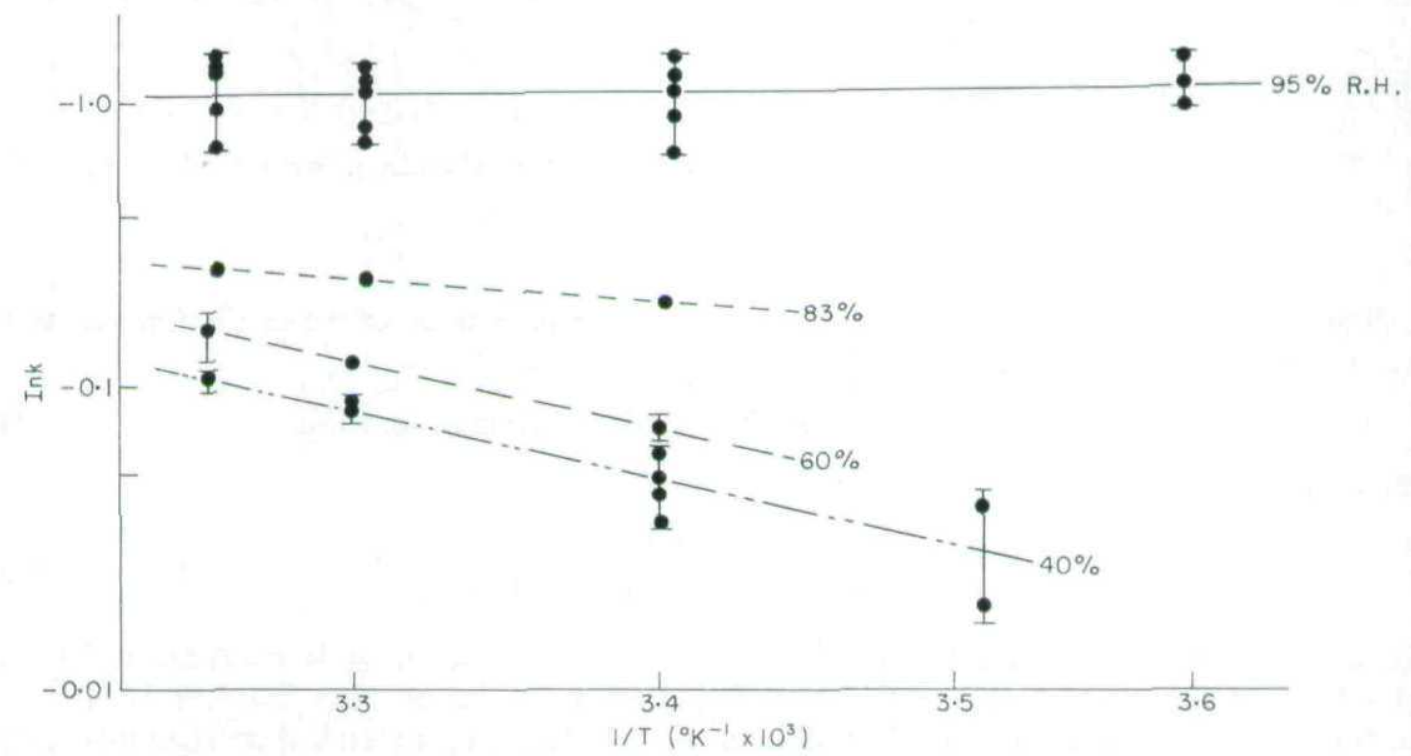

FIGURE 2 . Stratum corneum hydration equilibrium constant $\mathrm{K}$ as a function of $\mathrm{I} / \mathrm{T}$ at four relative humidities. Range of values showing inter-sample variation indicated by vertical bars. Slope = $-\Delta H^{\circ} / R$.

* Varying the estimate of maximum hydration does not have a significant effect on the relation between $\mathrm{k}$ and temperature. Changing 92 to $60 \%$ changes $\Delta \mathrm{H}$ less than the confidence limits shown in Fig. 3. 


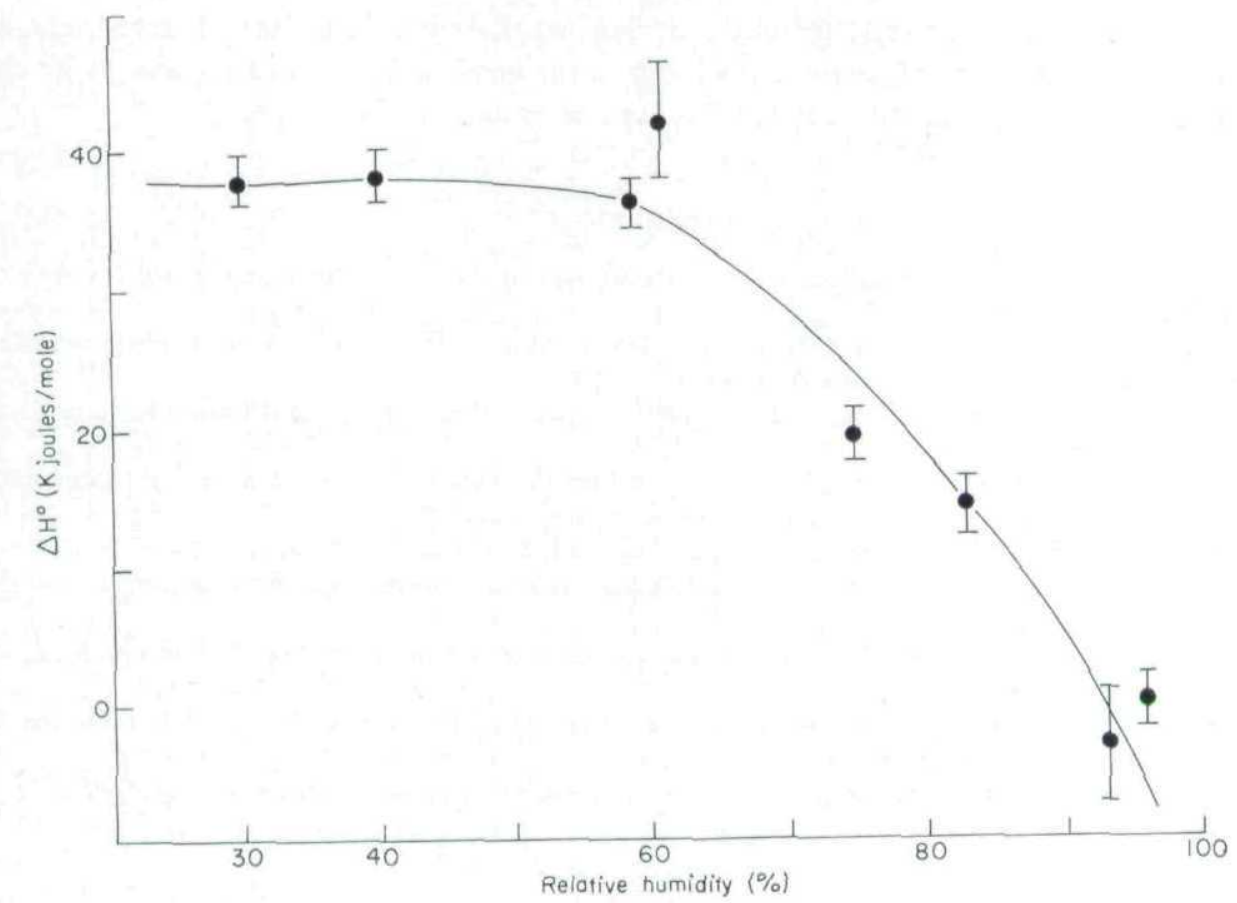

FIGURE 3. Enthalpy $\left(\Delta \mathrm{H}^{\circ}\right)$ of stratum corneum hydration equilibrium with $95 \%$ confidence limits indicated by vertical bars.

\section{DISCUSSION}

The enthalpy $\left(\Delta \mathrm{H}^{\circ}\right)$ associated with the stratum corneum-water equilibrium describes a temperature dependence of water content at lower RH. At RH below $60 \%$, stratum corneum rapidly loses its ability to retain water with decreasing temperature (Fig. I and Fig. 3). Although information on entropy is necessary before statements can be made concerning the overall heat of reaction, temperature dependence of hydration of stratum corneum is greater below $60 \% \mathrm{RH}$ than at higher $\mathrm{RH}$ (Fig. 3). This indicates that the nature of the bonds broken by water in the hydration process changes from low to high relative humidities. The first type of bond might correspond to water molecules hydrating strong higher-ordered bonds between stratum corneum protein molecules to give skin its pliability. As Blank (1952) indicated, this necessary water is approximately $10 \%$ at normal skin temperature (Fig. I). As RH increases, hydration above $10 \%$ involves water molecules which are bound less tightly (Scheuplein \& Morgan, I967). The change in $\Delta \mathrm{H}^{\circ}$ for hydration (Fig. 3) reflects a progressive change in the nature of the binding of water molecules as the stratum corneum absorbs more water. This additional hydration at $\mathrm{RH}$ above $60 \%$, however, is not necessary for normal pliability of skin.

In chapping and dry skin conditions, consideration must be given to the ability of skin to retain the $10 \%$ water necessary for pliability and extensibility. At $60 \% \mathrm{RH}$ and $30 \mathrm{C}$, water content of stratum corneum is only slightly above $10 \%$ (Fig. I), decreasing to approximately one-half this value at $20^{\circ} \mathrm{C}$. During colder winter months when the incidence of chapping increases (Gaul \& Underwood, 195I), stratum corneum could reasonably reach a surface temperature of $20^{\circ} \mathrm{C}$ or below when exposed to cold air. Lower temperature and lower relative humidity in winter could decrease the ability of 
stratum corneum to retain water, thereby reducing its pliability. Thus, the observed relationship between temperature and water content of stratum corneum should be considered along with changes in mechanical properties and environmental conditions as causes of dry skin.

\section{REFERENCES}

BLANK, I.H. (1952) Factors which influence the water content of the stratum corneum. fournal of Investigative Dermatology, 18, 433.

GAUL, L.E. \& UNDERWOOD, G.B. (I95I) Relation of dew point and barometric pressure to chapping of normal skin. Fournal of Investigative Dermatology, $\mathbf{1 8}, 9$.

KLigman, A.M. \& Christophers, E. (1963) Preparation of isolated sheets of human stratum corneum. Archives of Dermatology, 88, 702.

Middleton, J.D. \& Allen, B.M. (1973) The influence of temperature and humidity on stratum corneum and its relation to chapping. Fournal of Society of Cosmetic Chemists, 24, 239.

Moore, W.J. (1962) Physical Chemistry, p. I80. Prentice-Hall, Englewood Cliffs, U.S.A.

SCHEUPLEIN, R.J. \& MorgaN, L.J. (I967) 'Bound Water' in keratin membranes measured by a microbalance technique. Nature, 214, 456.

Singer, E.D. \& Vinson, L.J. (I966) The water binding properties of skin. Proceedings of Scientific Section, Toilet Goods Association, 46, 29.

WILDNAUER, R.H., BotHWELL, J.W. \& DovgLASS, A.B. (1971) Stratum corneum biomedical properties. fournal of Investigative Dermatology, 56, 72.

YouNG, J.F. (1967) Humidity control in the laboratory using salt solutions-a review. fournal of Applied Chemistry, 17, $24 \mathrm{r}$. 
This document is a scanned copy of a printed document. No warranty is given about the accuracy of the copy. Users should refer to the original published version of the material. 